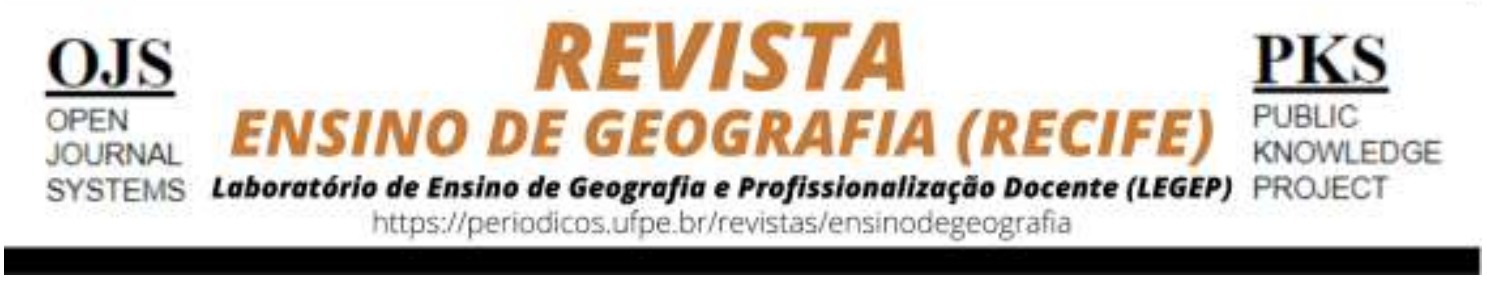

\title{
LITERATURA DE CORDEL: DESVENDANDO O LUGAR NA GEOGRAFIA ESCOLAR
}

\author{
Paulo Adriano Santos Silva1 ${ }^{1}$, Robertta De Jesus Gomes ${ }^{2}$
}

\begin{abstract}
${ }^{1}$ Membro da Academia Literária do Amplo Sertão Sergipano - ALAS. Doutorando e Mestre em Geografia Agrária pelo Programa de Pós-Graduação em Geografia da Universidade Federal de Sergipe. Especialista em Ensino de Geografia. Graduado em Geografia licenciatura pela Universidade Federal de Sergipe. E-mail: adriano_ufs@yahoo.com.br - ORCID iD: http://orcid.org/0000-0001-8232-24XX

2 Mestre pelo Programa de Pós-Graduação em Geografia (PPGEO/UFS). Graduada em Geografia Licenciatura pela Universidade Federal de Sergipe.E-mail: roberttadejesus@hotmail.com - ORCID iD: http://orcid.org/0000-0001-8232-2422
\end{abstract}

Artigo recebido em 12/06/2019 e aceito em 19/02/2020

\begin{abstract}
RESUMO
As reflexões didático-pedagógicas sugerem uma modificação na metodologia de ensino nas instituições escolares, baseadas na concepção de romper com o caráter tradicional que norteia as práticas vigentes. Diante disso, apresentamos como objetivo, analisar a importância da literatura de Cordel como ferramenta de leitura e entendimento da categoria analítica lugar, na Geografia Escolar. Utilizaremos a categoria geográfica lugar a partir de uma perspectiva das representações, buscando nas leituras e construções de cordéis, a percepção, o significado e os valores do meio. O cordel deve ser trabalhado nas aulas de Geografia no sentido de dinamizar as aulas e ao mesmo tempo valorizar essa arte popular nordestina. Como resultados esperamos que os educandos consigam apreender os conteúdos alusivos ao Nordeste brasileiro, estimulando à escrita e criatividade por meio da construção dos cordéis, e concomitantemente incitar o gosto pela leitura, pesquisa e, sobretudo, pelo estudo e entendimento da categoria geográfica lugar. O lugar, que nesse contexto torna-se, então, uma representação de múltiplas manifestações do espaço Geográfico.
\end{abstract}

Palavras Chave: Lugar; Literatura de Cordel; Geografia Escolar.

\section{CORDEL LITERATURE: DENVING THE PLACE IN SCHOOL GEOGRAPHY}

\begin{abstract}
The didactic and pedagogical reflections suggest a change in teaching methodology in schools, based on the concept of breaking with the traditional character that guides existing practices. Therefore we present to analyze the importance of Cordel literature as a tool for reading and understanding the analytical category place in educational Geography. We'll use the category geographical place from a perspective of representations seeking the readings and constructions of twine perception, meaning and values of the environment. The string must be worked in geography lessons on enhancing lessons while valuing this popular northeastern art. As a result we expect that students are able to grasp the content depicting the Brazilian Northeast, stimulating writing and creativity through the construction of twine, while also encouraging a love of reading, research and particularly the study and understanding of geographical place category. The place, which in this context, then, becomes a representation of multiple manifestations of Geographic Space.
\end{abstract}

Key words: Location, educational, Cordel Literature and Geography. 


\section{INTRODUÇÃO}

A crise da educação brasileira tem colocado novas exigências e responsabilidades a cargo dos professores e da escola como um todo no sentido de torná-la tão atraente tal qual se apresenta o mundo fora do ambiente escolar. Tais tendências são decorrentes das rápidas transformações que assolam o mundo contemporâneo, sendo desafio da escola acompanhar essas evoluções a fim de apresentar respostas superadoras da sua prática, frente a realidade da sociedade atual. Nesse ínterim, busca-se ressaltar a literatura de Cordel como ferramenta pedagógica facilitadora da leitura e compreensão da categoria geográfica Lugar. Destarte Pontuschka, Pagnelli e Cacete (2009) asseveram que essas práticas ampliam a possibilidade dos discentes compreenderem os conceitos com maior profundidade.

Verifica-se que o ensino básico brasileiro enfrenta muitas adversidades com as escolas degradas e professores com práticas tradicionais. Logo, essa realidade acaba por gerar a evasão, haja vista, que os alunos não se sentem incluídos no ambiente escolar. Dessa maneira buscamos propor estratégias metodológicas que os docentes podem aplicar com seus alunos de maneira lúdica e como salienta Kaercher (1999) a custo zero, ou seja, o professor não vai mudar toda a realidade da educação brasileira atual, porém são essas pequenas atitudes que em conjunto podem estimular uma grande transformação e tomada de consciência na sociedade perante o papel da escola no intuito de formar cidadãos críticos e agentes participativos.

Callai (2004) salienta que o mundo da vida precisa entrar para dentro da escola, para que esta também seja viva, para que consiga acolher os alunos e possa dar-lhes condições de realizarem a sua formação, de desenvolver um senso crítico, e ampliar as suas visões de mundo. Para que isto aconteça a escola deve ser a geradora de motivações para estabelecer inter-relações e produzir aprendizagens, e o professor, o mediador deste processo.

Ainda nessa linha de construção de uma educação cidadã destacamos a importância de trabalhar a partir da perspectiva cultural onde a literatura de cordel está inserida. Dessa maneira devemos romper com o receio de muitas escolas e professores de trabalharem com a geografia cultural, uma vez que, as práticas de ensino atreladas ao aspecto cultural apresentam um papel de enorme importância para a escola na defesa, promoção, difusão e conhecimento das manifestações culturais populares. Entretanto, talvez não esteja da 
mesma maneira claro para muitos de nós, a significativa contribuição que a perspectiva cultural pode trazer para a escola. (SILVA, 2008).

Pensando nisso retrataremos a literatura de cordel como uma ferramenta pedagógica que contribui para dinamizar as aulas de geografia no ensino médio, além de favorecer a reflexão acerca de conhecimentos obtidos mediante leitura ou exposição dos cordéis. Os cordéis irão representar o lugar, na perspectiva de Tuan (1980), enquanto palco das ações humanas, da percepção, da vivência, da experiência, e da imaginação, que formam um conjunto que vem a ditar o grau de significados que o homem lança ao seu espaço.

Azambuja (2011) enfoca que os educadores necessitam investir em práticas direcionadas a trabalhos manuais ou resoluções de problemas práticos e Kaercher (2011) também contribui com esse debate quando salienta que os docentes devem ressaltar o sentido da geografia no dia-a-dia dos alunos e, portanto, devem trabalhar com prazer por meio do que ele denomina de PDT "paixão, desejo e tesão" e dessa forma estimular os alunos a se tornarem mais participativos nas aulas de geografia, que em muitos casos é considerada enfadonha e decoreba.

Schäffer destaca que (2006, p.89), “para que o aluno venha ler e escrever em geografia é necessário, que antes, o professor dirija seu olhar para o outro (o aluno) e para o conjunto (a escola)". Igualmente, o papel do professor é o de mediar os conhecimentos dos discentes com os conteúdos de maneira a considerar a importância igual dos diversos agentes no processo da construção da aprendizagem.

Nessa perspectiva, propomos a construção de um projeto escolar visualizando na literatura de cordel uma possibilidade de trabalhar a categoria geográfica Lugar de uma forma lúdico-pedagógica. Ressaltamos que os professores devem abolir as práticas tradicionais e trabalhar com diferentes linguagens, para estimular o desenvolvimento das competências e habilidades dos discentes.

Entende-se práticas tradicionais como as formas de ensino de apenas repetir conteúdos, exercícios de memorização sem nenhuma reflexão sobre os conceitos geográficos. Nesse contexto, as diferentes linguagens surgem para deixar o ambiente escolar mais atraente, leve, lúdico. Porém é relevante mencionar que essas novas práticas de ensino devem estar atreladas aos conteúdos, para não se cometer o equivoco de pensar que o lúdico pelo lúdico somente gera aprendizado efetivo. Dessa forma Callai (2005) contribui com esse debate: 
É certo que, da forma como a geografia tem sido tratada na escola tradicionalmente, ela não tem muito a contribuir. Aquela geografia chamada tradicional, caracterizada pela enumeração de dados geográficos e que trabalha espaços fragmentados, em geral opera com questões desconexas, isolando-as no interior de si mesmas, em vez de considerá-las no contexto de um espaço geográfico complexo, que é o mundo da vida (CALLAI, 2005, p. 229-230).

Destarte,objetivamos analisar a importância da literatura de Cordel como ferramenta de leitura e entendimento da Geografia,bem como, refletir acerca da categoria de análise Lugar na Geografia escolar; trabalhar o conceito de lugar partindo da realidade dos discentes; abordar o histórico da literatura de cordel na região nordeste no âmbito das representações; identificar os cordéis que retratam os conteúdos da Geografia do Nordeste; debater sobre a relevância da literatura do cordel e valorizar essa manifestação cultural nordestina; fomentar a escrita de cordéis relacionando com os conteúdos geográficos e, por fim,analisar a importância do cordel no ensino-aprendizagem da Geografia escolar a partir da categoria geográfica lugar.

No sentido de facilitar a compreensão deste artigo, dividimo-lo em duas partes, além desta introdução e das considerações finais. Na primeira seção, fizemos uma análise teórica sobre as representações do lugar na Geografia Escolar, demonstrando os desafios e as perspectivas atuais na educação básica. Na segunda parte do texto construímos um breve debate sobre a literatura de cordel como ferramenta lúdico-pedagógica e, em seguida, propomos a realização de um projeto escolar envolvendo a construção de cordéis como forma de facilitar o entendimento da leitura e compreensão dos processos geográficos que configuram a produção do lugar.

\section{AS REPRESENTAÇÕES DO LUGAR NA GEOGRAFIA ESCOLAR}

Retomemos Tuan (1983) para refletir acerca do lugar quando este destaca a importância da geografia cultural ao estudar a categoria lugar a partir do significado que as pessoas atribuem ao mesmo. Nesse sentido, "a categoria lugar não menospreza o real, o vivido e abre caminho para o discente estabelecer relações com outros lugares e com o mundo" (STRAFORINI, 2006, p.94).

Helena Callai, trabalhando o lugar como possibilidade de construção da identidade e pertencimento de um povo, afirma que: 
Este lugar é um espaço construído como resultado da vida das pessoas, dos grupos que nele vivem, das formas como trabalham, como produzem, como se alimentam e como fazem/usufruem do lazer. É uma vida de determinados grupos sociais, ocupando um certo espaço num tempo singularizado. Considerando que é no cotidiano da própria vivência que as coisas vão acontecendo, vai se configurando o espaço, e dando feição ao lugar, um lugar que é um espaço vivido, de experiências sempre renovadas o que permite que se considere o passado e que se vislumbre o futuro. A compreensão disto necessariamente resgata os sentimentos de identidade e pertencimento. (CALLAI, 2004, p. 02).

Desse modo, evidencia-se que "é o homem o sujeito, o produtor do espaço. Essa construção está estreitamente vinculada as relações sociais, políticas, ideológicas, culturais. Esta implica em um modo de produzir, de pensar, de sentir, enfim, em um modo de vida" (ALMEIDA, 2006, p. 115), compreendido como um espaço imaterial permeado de significados e sentidos que configuram a produção do lugar no contexto de representações cotidianas. "o lugar nos identifica como indivíduos com características culturais diferentes de outros que vivem em outro lugar" (BUENO E CALLAI,2009, p. 9).

Os elementos que compõe o lugar caracterizam-se por constituir e agregar características materiais e imateriais que portam simbolismo evidenciado no cotidiano, a partir da representação das manifestações do indivíduo. Nesse cenário, as vozes, as imagens, os sujeitos integram numa dada realidade constituída num tempo e num espaço elaborado a partir de relações impressas pela identidade do homem com o meio.

Hall (2002) reforça essa ideia de forte conexão entre identidade e lugar quando afirma que o ser humano carrega em sua vida uma série de significados e valores que são influenciados pelas relações de pertencimento com os lugares. Destarte, a noção de pertencimento com o lugar, como salienta Oliveira (2012), é demonstrado a partir dos sentimentos identitários que remetem a memória e aos lugares.

Corroborando com as discussões sobre a relação identitária do indivíduo com o lugar, Callai (2004), destaca a importância da escola enquanto instituição viva, presente no cotidiano dos discentes e aponta que:

A escola se apresenta como a possibilidade de busca/investigação e produção
de conhecimento. Um conhecimento que sirva para a vida do aluno, tanto na
perspectiva de se reconhecer como um sujeito que tem uma identidade e que
perceba o seu pertencimento, tanto quanto um desenvolvimento cognitivo que
lhe permita ler o mundo, trabalhar nele tendo as condições necessárias e viver
de modo decente (CALLAI, 2004, p. 3).

O uso de metodologias lúdico-pedagógicas instiga a participação dos alunos, algo não possibilitado a partir do ensino mnemônico. Logo, para facilitar a assimilação de 
diversas temáticas Pontuschka, Pagnelle e Cacete (2009) ressaltam a relevância da realização de projetos pautados na interdisciplinaridade, contudo também alertam que essa atividade não pode ser um objeto pronto e que deve contar com a participação de diversos professores, a fim de formar um trabalho conjunto em todas as etapas desde sua idealização. Além disso, ela destaca a importância de se trabalhar com um tema gerador que tenha um contato estrito com a realidade local. Assim, o conhecimento disciplinar da geografia quando é articulado interdisciplinarmente, chega a um entendimento enriquecido daquela realidade local complexa e contraditória. Assim:

Um avanço no pensar interdisciplinar ocorre quando os professores de áreas afins definem um tema de interesse comum e passam a trabalhar em conjunto, com o olhar experimentado de cada especialista, mediante a utilização de métodos e técnicas de cada disciplina para a maior compreensão dos fatos, fenômenos e situações do mundo atual. (PONTUSCHKA, PAGNELLE E CACETE, 2009, p.152).

Ainda sobre a interdisciplinaridade Selbach (2010) destaca que trabalhar a geografia como uma "ferramenta" interdisciplinar não significa que o docente tenha que conhecer todos os elementos das outras disciplinas, mas deve saber propor desafios aos discentes a fim de estimulá-los a estabelecer as ligações ou conexões. E, para a utilização de novas metodologias de ensino, deve-se partir do pressuposto que as escolas ainda possuem dificuldade em lidar com a movimentação e com novas práticas que saiam da sala de aula, visto que para alguns educadores tradicionais isso representa desordem e desse modo essas expressões dos alunos e sua criatividade são pouco aproveitadas. (SILVA, 2008).

De tal modo pensamos também em inserir no projeto o Estudo do lugar, já que segundo Pontuschka, Pagnelli e Cacete (2009) o trabalho de campo torna-se essencial na medida que é a partir do mesmo que podemos atrelar os conteúdos estudados em sala de aula à realidade, ampliando assim, nesse caso, a análise sobre o espaço a partir da abordagem cultural da geografia. Nesse sentido, Braun (2005) afirma que o trabalho de campo é um caminho metodológico que possibilita articulações entre diversos campos das geografias e tem como finalidade facilitar a compreensão do mundo atual.

Consideramos que para além dos muros das escolas tal prática é importante no processo de facilitação, compreensão e relação dos conteúdos, tendo em vista que o mesmo proporciona aos discentes a vivência concreta, bem como a leitura do ambiente analisado. 
Conforme Braun (2005) prática de campo é "[...] uma possibilidade de metodologia que não apenas relaciona teoria e prática, mas possibilita e oportuniza a construção do conhecimento a partir do significado da realidade, do engajamento no concreto e da compreensão da totalidade-mundo".

Silva (2014) salienta que toda atividade que proporciona a construção de conhecimento em ambiente externo ao das quatro paredes deve ser executada, seja através da concretização de experiências que promovam a observação, ou da interpretação do espaço, e suas formas de organização, inerentes a prática social onde os sujeitos atuam constantemente na produção do espaço. Nesse ínterim a ideia de lugar enquanto representação na geografia escolar é aproveitada nessas atividades de campo.

Dessa forma, a construção de cordéis também será inserida no projeto, uma vez que, os discentes irão construir o cordel a partir de suas percepções do lugar. Esse tipo de ferramenta é relevante nas práticas de ensino, pois busca instigar a criatividade dos alunos. Logo, Ribeiro (2011, p.74) assevera que "é necessário ousarmos em realizar atividades que saiam do "chão", já vamos encontrar por muitos anos a mesma escola, com a mesma prática pedagógica, a mesma geografia e essa sem recheio, sem gosto". Nessa direção, ponderamos que a literatura de cordel é uma ferramenta para retirar os educandos das carteiras da sala de aula e colocá-los como protagonistas ou agentes no seu processo de aprendizagem, pois os discentes são estimulados a construir as rimas e as imagens do Cordel que são conhecidas como xilogravuras e depois pendurá-las em uma linha de barbante no corredor da escola.

Segundo Ferreira (2008) a literatura de Cordel é tipicamente da região Nordeste e podemos encontrá-la de diferentes formas: em músicas, repentes, teatro, filmes, entre outros. Portanto esse é um recurso que pode ser muito utilizado nas aulas de geografia para torná-las mais dinâmicas. Consequentemente, o cordel torna-se importante no exercício da construção da aprendizagem, pois consegue suscitar dos discentes uma maior participação e interação.

Lopes (2009) ressalta que a região nordeste nos livros didáticos de geografia é colocada de forma equivocada com muitos conceitos que denigrem a imagem do Nordestino colocando-o como preguiçoso fadado à pobreza e a baixa qualidade de vida.

Trabalhar a Geografia com atividades lúdicas é uma alternativa estratégica para os docentes, essas práticas permitem aos alunos fazer uma relação e reflexão dos conceitos geográficos, proporcionando assim um incentivo para a busca do 
conhecimento. Estimulados, a prática de ensino e aprendizagem da geografia torna-se prazerosa tanto para o próprio professor como para o aluno. Além disso, o discente fazse presente de modo ativo na construção do conhecimento, substituindo a educação bancária, na qual os educandos memorizam os conceitos prontos, sem fazer a reflexão necessária. Diante disso Freire (1975) nos ajuda ao afirmar que:

O importante, do ponto de vista de uma educação libertadora, não "bancária", é que em qualquer dos casos, os homens se sintam sujeitos de seu pensar, discutindo o seu pensar, sua própria visão do mundo, manifestada implícita ou explicitamente, nas suas sugestões e nas de seus companheiros (FREIRE, 1975, p.141).

É fundamental que os mediadores do conhecimento superem a ideia do ensino tradicional e insiram no contexto educacional uma visão "investigativa", como ressalta Passini (2011, p. 37) “temos que nos atualizar e virar a página da geografia descritiva para discutirmos os fatos geográficos numa abordagem analítica e crítica. A nossa proposta é o desenvolvimento de circunstância" de modo que os discentes consigam visualizar as relações e sistematizá-las no sentido de entender a dinâmica socioespacial contemporânea, partindo da categoria lugar. O processo descritivo não deve ser totalmente excluído ,uma vez que este é usado nos trabalhos de campo, a discussão levantada é que o discente não aprenderá somente com esse processo descritivo, e sim com o apoio das outras fases do processo de aprendizado, interpretando os dados coletados, compartilhando com colegas e analisando o espaço geográfico como um todo.

\section{A LITERATURA DE CORDEL NA GEOGRAFIA ESCOLAR: UMA PROPOSTA LÚDICO-PEDAGÓGICA}

As reflexões didático-pedagógicas sugerem uma modificação na metodologia de ensino nas escolas, baseadas na concepção de romper com o caráter tradicional que norteia as práticas vigentes. Para Pontuschka (2009) na Geografia, é necessário o professor compreender o que é uma prática tradicional de ensino e uma prática renovada, processos esses que acompanham a trajetória da própria. Assim, é importante o educador seguir teorias de aprendizagem que possibilitem o desenvolvimento de atividades lúdicopedagógicas que permitam a construção de conhecimentos pelo aluno. Nesse contexto, Silva, et. al, aponta que:

Nas últimas décadas, a Ciência Geográfica passou por uma série de mudanças no tocante aos seus métodos de analisar as relações que se estabelecem no espaço geográfico. Atrelado a essas alterações, o ensino dessa ciência tem sido 
motivo de discussão e modificações, tendo em vista a busca pelo acompanhamento da dinâmica espacial (SILVA, et. al, p. 04, 2013).

O ensino mnemônico precisa ser substituído, abrindo assim espaço para práticas condizentes com a formação de alunos mais articulados e conhecedores da realidade em que vivem. Castrogiovanni (2009) assevera que, na contemporaneidade a análise, compreensão e representação do espaço, tempo e sociedade é fundamental na escola ao tecermos a aproximação do teórico/acadêmico com a reflexão do cotidiano vivenciado pelo estudante. $\mathrm{O}$ educador precisa estimular os seus alunos a exercitar o olhar espacial no qual os aspectos essenciais são a observação, reflexão e análise do lugar.

Nesse sentido, pensamos numa proposta de projeto de ensino diferenciado haja vista que a educação carece de uma inovação na qual os docentes deixem as práticas tradicionais e trabalhem com metodologias de ensino lúdico-pedagógicas. Antunes (2010) assevera a necessidade de se trabalhar através do estimulo a curiosidade e o desenvolvimento de diversas habilidades dos discentes, despertando, dessa maneira, o interesse e o aprendizado. Logo, o professor moderno, aquele educador que utiliza variadas metodologias de ensino vinculadas ao aprendizado significativo, que ouve os seus discentes, que se opõe a educação bancária de apenas depósito dos conteúdos nos estudantes sem um debate reflexivo, esse profissional deve buscar sempre essas novas ferramentas de ensino que ascendam nos educandos a ânsia pelo conhecimento e que desenvolvam diversificadas potencialidades.

Dessa maneira, apresentamos, enquanto proposta pedagógica, o desenvolvimento de um projeto que busque estimular os educandos a reflexão sobre os aspectos geográficos partindo dos seus próprios lugares. E, dentro desse contexto, ressaltamos a importância da literatura de cordel como uma ferramenta lúdico-pedagógica que contribui para dinamizar as aulas de geografia no ensino médio, além de favorecer a reflexão e o entendimento acerca dos conteúdos Geográficos.

\subsection{METODOLOGIA DO PROJETO DE ENSINO}

A trajetória do projeto de ensino/pesquisa, em nossa proposta, deverá envolver inicialmente uma vasta revisão bibliográfica por meio de consultas a livros, artigos e dissertações vinculados à temática sobre ensino de Geografia, Literatura de Cordel e a Categoria Geográfica Lugar. 
Nesse direcionamento, o projeto deverá ser desenvolvido com alunos da $2^{\mathrm{a}}$ série do ensino médio, no período de três semanas e terá a seguinte sequência:

- $\mathbf{1}^{\text {a }}$ Aula: Apresentação e reelaboração conjunta do projeto (docentes e discentes)

- 2a Aula: Explanação histórica do surgimento e da estrutura da literatura de cordel (Figura 1) com ênfase na Região Nordeste Brasileira (interdisciplinaridade com os professores de literatura e português). Nesse contexto, as atividades que partem de ações interdisciplinares são essenciais no ensino básico e, além disso, torna-se relevante mencionar que essa ação deve ser bem planejada em todos os momentos do projeto.

Nesse ínterim, Antunes (2010, p.175) coloca que "a ação interdisciplinar do professor não pode se reduzir a acidente fortuito e ocasional, mas trabalho contínuo, atemporal e persistente.” Portanto, a pratica interdisciplinar é essencial e para que surta efeitos positivos, depende da cooperação e persistência entre todos os sujeitos envolvidos na construção e execução do referido projeto.

- $3^{\text {a }}$ Aula: Na terceira aula sugerimos que seja feita uma leitura e canto dos cordéis na sala de aula, relacionando com os conteúdos trabalhados na disciplina (Região Nordeste);

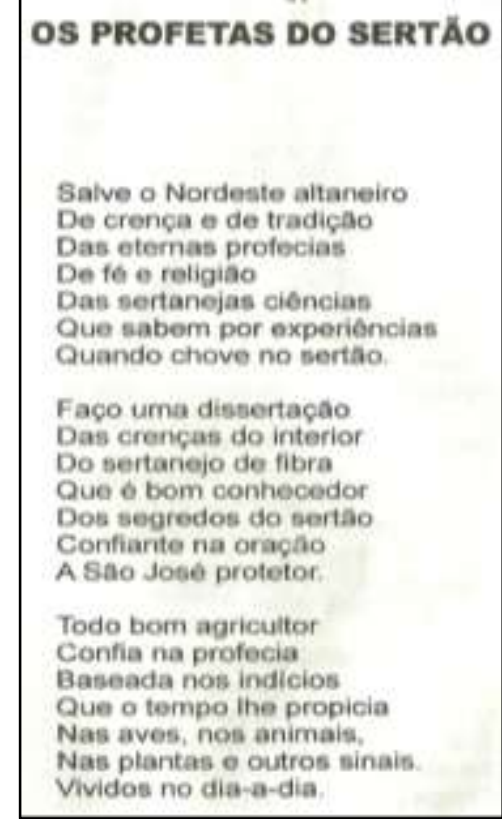

Fonte: Zé Antônio (Cordelista e Professor de História), 2013.

- $4^{\text {a }}$ e $5^{\text {a }}$ Aula: Propõe-se um trabalho de campo no sentido de trabalhar a parte empírica do projeto. Braun (2005) assevera que a prática de campo é “[...] uma 
possibilidade de metodologia que não apenas relaciona teoria e prática, mas possibilita e oportuniza a construção do conhecimento a partir do significado da realidade, do engajamento no concreto e da compreensão do espaço". O Trabalho de campo será desenvolvido em três momentos e lugares: no Mercado Central de Aracaju, no Museu da Gente Sergipana e em Feiras livres. Nosso campo buscará os cordelistas (os cordéis, os idosos e os turistas). O registro a partir de entrevistas, vídeos e fotos, bem como a construção de Cordéis pelos alunos a partir do trabalho de campo. Nesse momento do projeto estaremos abertos a sugestões que serão escolhidas pela maioria dos alunos após a apresentação inicial do projeto.

- Cabe abrir uma aula para explorar o lugar, a partir dos espaços trabalhados no campo, como representação da cultura popular nordestina.

- Na $6^{\text {a }}$ Aula, faremos o registro e organização dos dados a partir de entrevistas, vídeos e fotos coletados. Ao retornarmos à sala de aula, discutiremos com os discentes sobre a importância do trabalho de campo na relação entre teoria e prática. Posteriormente iremos trabalhar no sentido de tabular e sistematizar todos os dados coletados no campo a partir das entrevistas, fotografias, imagens, entre outras informações.

- Na $7^{a}$ Aula, será realizada a etapa final do projeto com a socialização do aprendizado, a partir de oficinas de construção de cordéis e exposição, em forma de varal, no pátio da escola.

\subsection{RECURSOS DIDÁTICOS:}

- Cartolina, Pincel, Cola, Papel, Lápis de Cor, Barbantes e Pregadores.

\subsection{RESULTADOS ESPERADOS:}

Com a aplicação destas oficinas pedagógicas espera-se que:

- Os educandos consigam apreender os conteúdos alusivos ao Nordeste brasileiro, estimulando a escrita e a criatividade por meio da construção dos cordéis, e incitar o gosto pela leitura, pesquisa e, sobretudo pelo estudo da categoria geográfica lugar;

- Seja um momento de experiências diversificadas, com o intuito de valorizar a contribuição dos negros, índios e brancos, a exemplo dos festejos juninos, da culinária, das danças, dos rituais religiosos e demais tradições que compõem a cultura do nordeste; 
- Contribuir para a construção da geografia escolar, um saber amplo que auxilie o educando no seu posicionamento frente ao mundo contemporâneo;

- Despertar o interesse pelo ensino da Geografia a luz da inclusão de novos procedimentos de ensino e recursos didáticos na perspectiva de romper com o modo de abordagem tradicional dessa disciplina comumente usado em sala de aula;

- Possibilitar aos discentes a compreensão das relações que se estabelecem no espaço geográfico e sua relação com a cultura do lugar.

\section{CONSIDERAÇÕES FINAIS}

Em virtude do que foi posto, verificamos, um momento de multiplicidade e experiências, muitas vezes alternativas, em que o professor, em grande medida, vai aprendendo que pode criar e inovar, que pode contribuir para a construção de uma nova educação escolar, um saber crítico que auxilie o educando no seu posicionamento frente ao mundo em que vive (VESENTINI, 1991).

Consideramos que a literatura de cordel é uma ferramenta essencial na leitura e entendimento da categoria analítica lugar na Geografia Escolar. Para além da dinamização nas aulas de geografia, o cordel deve ser trabalhado no sentido de valorizar essa arte popular nordestina e, de acordo com Silva (2015, p. 05), reforçar o "sentimento de "identidade socioterritorial" que é construído pelos sujeitos a partir das relações e tradições, ainda que ressignificadas, na contemporaneidade".

Nessa perspectiva, Silva (2011) aborda sobre os saberes que identificam ou qualificam um bom professor como, por exemplo, a ousadia, criatividade e determinação em propor novas práticas. Assim vale comentar que o docente deve sempre buscar trabalhar a partir da interdisciplinaridade e do sentido, ou seja, a importância da geografia para si e para os seus educandos a fim de tornar o conhecimento da ciência geográfica algo mais prazeroso e pertinente para ambos os atores do processo de ensino/aprendizagem. 


\section{REFERÊNCIAS}

ALMEIDA, Maria Geralda. A Produção do Ser e do Lugar Turístico. In: SILVA, José. B.; LIMA, Luiz. C.; ELIAS, Denise. (Org.). Panorama da Geografia Brasileira 1. São Paulo: Anna Blume, 2006, p. 109-122.

ANTUNES, Celso (coord.). Geografia e Didática/Simone Selbach (Supervisão geral)Petrópolis, RJ:Vozes,2010. (Coleção Bem Ensinar).

AZAMBUJA. Leonardo de A. Metodologias cooperativas para ensina e aprender Geografia. In: CALLAI, Helena Copetti (Org). Educação Geográfica: Reflexão e Prática. IJUÍ/RS: UNIJUI. 2011, p. 185-210.

BRAUN, Ani Maria Swarowsky. Rompendo os muros da sala de aula: O Trabalho de Campo como uma linguagem no ensino de Geografia. Dissertação de Mestrado. Universidade Federal do Rio Grande do Sul. Porto Alegre, Junho de 2005.

BUENO, Thiago da Silva; CALLAI, Helena. AGeografia da vida cotidiana. In: $16^{\circ}$ Encontro Nacional de Ensino em Geografia. Porto Alegre, 2009.

CALLAI, H. C. O estudo do Lugar como possibilidade de construção da identidade e pertencimento. Anais do VIII Congresso luso-Afro-Brasileiro de Ciências Sociais. Coimbra, 2004.

CALLAI, Helena Copetti. Aprendendo a ler o mundo: a geografia nos anos iniciais do ensino fundamental. Cad. CEDES, Campinas, v. 25, n. 66, p. 227247, Aug. 2005. Disponível em: $<$ http://www.scielo.br/scielo.php?script=sci_arttext\&pid=S0101$32622005000200006 \& \operatorname{lng}=e n \& n r m=i s o>$.Acesso em 08 de Fevereiro de 2020.

CASTROGIOVANNI, Antonio Carlos. O LUGAR DA GEOGRAFIA NO ENTRELUGAR DO ESPAÇO TURÍSTICO Uma viagem complexa que ainda continua.. ROSA DOS VENTOS-Turismo e Hospitalidade, v. 1, 2009.

FERREIRA, Evyllaine Matias Veloso. A literatura de Cordel como recurso didático cultural no ensino de geografia, 2008.

FREIRE, Paulo. Pedagogia do Oprimido. três ed. Rio de Janeiro: Paz e Terra, 1975.

HALL, Stuart. A identidade cultural na pós-modernidade. Tradução Tomaz T. Silva e Guacira L. Louro. $7^{\text {a }}$ edição. Rio de Janeiro. 2002. 102p.

KAERCHER, N. (Orgs.)A. Geografia: práticas pedagógicas para o ensino médio. Vol.2. Porto Alegre: Penso, 2011, p.122-144.

KAERCHER, Nestor André. Estudos Sociais: Reflexões, Críticas e Desafios.In: CASTROGIOVANNI, A. Carlos. Geografia em sala de aula: práticas e reflexões. Porto alegre, AGB, 1999. 
LOPES, Lucineide Fábia Rodrigues. A Região Nordeste nos livros didáticos de geografia: uma análise histórica / - João Pessoa: [s.n.], 2009.

OLIVEIRA. Livia. O sentido do Lugar. MARANDORA JR. Eduardo, holzerWerther.OLIVEIRA. Livia (Orgs.). Qual o espaço do lugar. São Paulo: Perspectiva, 2012, p. 03-16.

PASSINI, Elza Yasuko. Convite para inventar um novo professor. IN: PASSINI, Elza Yasuko; PASSINI, Romão; MALYSZ, Sandra T. (orgs). Práticas de ensino de geografia e estágio supervisionado. $2^{\mathrm{a}}$ ed - São Paulo: Contexto, 2011.

PONTUSCHKA, NídiaNacib. PAGANELlE, TomokoIyda. CACETE, NúriaHanglei. Para ensinar e aprender Geografia. $3^{\circ}$ ed. São Paulo: Cortez, 2009.

RIBEIRO, Emerson. A criatividade em geografia, prática pedagógica e avaliação: lanternas geográficas. Geosaberes: Revista de Estudos Geoeducacionais, v. 2, n. 4, p. 61-75, 2011.

SCHÄFFER, Neiva O. Ler a paisagem, o mapa, o livro...escrever nas linguagens da geografia. In: NEVES. I.C.B. SOUZA J.V. SHÄFFER N. O. GUEDES P.C. KLÜSENER R. (Orgs.) Ler e escrever: compromisso de todas as áreas. $7^{\mathrm{a}}$ ed. Porto Alegre: EUFRGS, 2006, 86-103.

SELBACH, Simone et al. Geografia e didática. Petrópolis, RJ: Vozes, 2010.

SILVA, Jorge Luiz Barcellos. Quais saberes constituem um bom professor de Geografia. O Ensino de Geografia e suas composições curriculares. Porto Alegre: Mediação, p. 215-226, 2014.

SILVA, Paulo Adriano Santos. Território: abordagens e concepções. In: Boletim DATALUTA - São Paulo, Artigo do mês: dezembro de 2015. P. 01 - 07. ISSN 2177 4463.

SILVA, Paulo Adriano Santos; GOMES, Robertta de Jesus; MENEZES, Sônia de Souza Mendonça. Novas Proposições Metodológicas para o ensino de Geografia: relatos de experiência no Estágio Supervisionado. In: Geosaberes, Fortaleza, v. 4, n. 8, p.3 -13, jul. / dez. 2013.

TUAN, Yi-fu. Espaco e lugar: a perspectiva da experiência. São Paulo: DIFEL, 1983.

TUAN, Yi-Fu. Topofilia; um estudo da percepção, atitudes e valores no meio ambiente. São Paulo: Difel, 1980.

VESENTINI, José William. Para uma crítica na Escola. São Paulo, 1991.

VESENTINI, José William. VLACH, Vânia. Geografia Crítica. 4ª ed. São Paulo: Ática, 2009 . 